\title{
O Método Psicanalítico de Pesquisa e a Potencialidade dos Fatos Clínicos
}

\author{
Clarice Moreira da Silva \\ Mônica Medeiros Kother Macedo \\ Pontifícia Universidade Católica do Rio Grande do Sul, Pontifícia Universidade Católica do Rio Grande do Sul, \\ RS, Brasil. \\ RS, Brasil.
}

Resumo: Este artigo tem como objetivo discorrer sobre uma modalidade de pesquisa com o método psicanalítico. Para tanto, apresenta-se um processo de sistematização para sua execução, partindo-se de elementos teóricos, técnicos e éticos que permitem a atenção aos elementos essenciais da Psicanálise. Explora-se, desta forma, uma possibilidade de efetiva aplicação do método de pesquisa psicanalítico no cenário acadêmico a partir da proposta de elaboração de fatos clínicos. As etapas do processo de construção dos fatos clínicos já indicam os fundamentos teóricos nos quais esses se sustentam, marcando, assim, a diferença de uma descrição clínica ou de um estudo de caso. Tomando-se como ponto de partida o recurso à Psicanálise como método de investigação dos fenômenos humanos, os fatos clínicos, constituídos a partir da experiência analítica do psicanalista pesquisador, presentificam a dialogia do campo analítico. A pertinência de pesquisas com o método psicanalítico é reforçada na afirmação de que, por meio delas, é evidenciada a vitalidade da escuta e da postura investigativa psicanalítica. Nesta direção, o artigo fornece elementos que têm como objetivo estimular fortemente a investigação em Psicanálise, considerando-a uma relevante forma de seguir trabalhando e ampliando o legado freudiano.

Palavras-chave: Pesquisa, Metodologia, Psicanálise, Fatos Clínicos.

\section{The Psychoanalytic Method of Research and the Potential of Clinical Facts}

\begin{abstract}
This article aims to discuss the type of research that uses the psychoanalytic method. Therefore, a systematic process for its implementation is presented, starting from the theoretical, technical and ethical elements that allow the attention to the key elements of Psychoanalysis. Thus, the article explores the possibility of an effective application of the psychoanalytic research method in an academic setting from the development proposal of clinical facts. The stages of construction process of the clinical facts already indicate the theoretical foundations on which these are sustained, marking the difference between a clinical description and a case study. Taking as starting point the use of psychoanalysis as a method of investigation of human phenomena, the clinical facts - constituted from the analytic experience of the psychoanalyst researcher - evoke the dichotomy of the analytical field. The relevance of the researches conducted with the psychoanalytic method is enhanced by the statement that, through them, it is evident how vital are the psychoanalytic listening and investigative approaches. In this sense, this article provides elements that strongly aim to stimulate research in psychoanalysis, considering it a relevant way to continue working and expanding the Freudian legacy.
\end{abstract}

Keywords: Research, Methodology, Psychoanalysis, Clinical Facts. 


\title{
El Método Psicoanalítico de Investigación y la Potencialidad de los Hechos Clínicos
}

\begin{abstract}
Resumen: Este artículo tiene como objetivo discurrir sobre una modalidad de investigación con el método psicoanalítico. Se presenta un proceso de sistematización para su ejecución, partiéndose de elementos teóricos, técnicos y éticos que consideran los elementos esenciales del Psicoanálisis. Se explora, de esta forma, una posibilidad de aplicación efectiva del método de investigación psicoanalítico en el escenario académico a partir de la propuesta de elaboración de hechos clínicos. Las etapas del proceso de construcción de los hechos clínicos ya indican los fundamentos teóricos en los cuales ellos se sostienen, diferenciándolos así, de una descripción clínica o de un estudio de caso. Tomándose como punto de partida el recurso al Psicoanálisis como método de investigación de los fenómenos humanos, los hechos clínicos, constituidos a partir de la experiencia analítica del psicoanalista investigador, demuestran la fertilidad del campo analítico. La pertinencia de investigación con el método psicoanalítico es reforzada en la afirmación de que, por medio de ellas, se evidencia la vitalidad de la escucha y de la postura investigativa psicoanalíticas. En esta dirección, el artículo ofrece elementos que tienen como objetivo estimular fuertemente la investigación en Psicoanálisis, considerándola una forma relevante de seguir trabajando y ampliando el legado freudiano.
\end{abstract}

Palabras Clave: Investigación, Metodología, Psicoanálisis; Hechos Clínicos.

\section{Introdução}

A Psicanálise, compreendida como uma disciplina científica, comporta bases epistemológicas e éticas para a realização de uma pesquisa. Para tanto, diferenciam-se a pesquisa em Psicanálise e a pesquisa com o método psicanalítico, com características e objetos de estudo distintos. O presente artigo objetiva apresentar uma modalidade de pesquisa com o método psicanalítico, propondo uma sistematização para sua aplicação, que parte de concepções e coordenadas teóricas, técnicas e éticas, decorrentes de sua aplicação em um processo de investigação no cenário acadêmico-universitário.

Inegavelmente constata-se na história da Psicanálise o movimento freudiano inicial de incluir a Psicanálise na denominação de ciência e, assim, afastá-la de qualquer atributo de saber especulativo. Moraes e Macedo (2011) consideram que a descoberta do Inconsciente e os desdobramentos relativos ao uso de um método para acessá-lo levaram Freud a afastar-se, de forma progressiva e definitiva, da epistemologia científica positivista do final do século XIX. Neste processo de distanciamento da Psicanálise em relação ao discurso científico vigente, para Birman (1992), "o saber psicanalítico, como um discurso com a pretensão intelectual de se inscrever no logos da ciência, se deslocou para outro lugar simbólico, onde pretendia ser reconhecido como uma ética" (p. 29). Trata-se, segundo o autor, não de uma ética como uma moral, mas, sim, de uma ética do desejo que funda o sujeito desde a concepção do Inconsciente. Logo, para a Psicanálise, são os impasses e a complexidade reconhecidos e afirmados nos meandros do desejo que instituem, definitivamente, seu caráter investigativo.

Ressalta-se a importância da realização de pesquisas com o método psicanalítico, uma vez que nessa condição pode ocorrer uma profícua forma de aproximação da Psicanálise com a Universidade. Nessa modalidade de encontro, reafirma-se a amplitude do corpo teórico e técnico psicanalítico, bem como sua inegável condição ética de promover o avanço e a produção de conhecimento, também, a partir de estudos realizados no âmbito da universidade. Constata-se, portanto, a rica possibilidade de a Academia acolher as inquietações geradas no exercício clínico da escuta psicanalítica.

\section{Especificidades da Psicanálise como método investigativo}

Na história da Psicanálise, Freud sempre manteve uma postura investigativa, partindo da experiência 
clínica para pensar sistematicamente reconfigurações teóricas e técnicas. A metapsicologia freudiana se constituiu e se solidificou nesses movimentos de abertura a transformações. O exercício clínico suscitou questionamentos à teoria e alavancou importantes transformações e ampliações tanto teóricas quanto técnicas. Destaca-se a afirmativa de Freud (1915/1996) sobre a necessidade constante de trabalho na produção de conhecimento: "o avanço do conhecimento não tolera qualquer rigidez, inclusive em se tratando de definições" (p. 123).

Afirma Conte (2004), por meio da escrita de historiais clínicos e da interpretação dos sonhos, que Freud ensinou a correlação entre a clínica e a teoria. Aponta-se, nesse contexto, que os casos de pacientes estudados inicialmente por Freud e Breuer, nos "Estudos sobre a histeria" (Freud, 1895/1996), bem como a análise de seus sonhos e o fracasso do caso Dora (Freud, 1905/1996), explicitam como o método de investigação freudiano foi proporcionando a montagem da teoria psicanalítica (Conte, 2004).

Nessa direção, Dunker (2011) enfatiza que o método de investigação fundamenta o método de tratamento, mantendo uma ligação de mútua utilidade prática e teórica. Ainda que diferentes um do outro, o ponto comum entre os dois distintos métodos é a transferência. O método de investigação é uma estrutura aberta, em função da heterogeneidade de fontes, pela diversidade de meios e pela comunicação com outros discursos e estratégias de investigação. Nesta metodologia investigativa, é sustentada a temporalidade da escrita, já o método de tratamento exige regras próprias ao universo verbal da fala. A ligação entre os dois métodos localiza a peculiaridade epistemológica da Psicanálise de ser, ao mesmo tempo, uma forma de discursividade e uma ciência (Dunker, 2011).

Segundo Conte (2004), Freud iniciou seu trabalho como método de investigação de sintomas, até chegar a um método de tratamento e à proposição de uma nova ciência. Ao retirar o foco e distanciar-se de uma concepção consciencialista e de uma lógica causal na compreensão dos fenômenos humanos, a Psicanálise se consolida como uma nova modalidade de investigação, cujas técnicas também seguem uma especificidade ao aproximar-se de seu complexo objeto de estudo: o Inconsciente. Como afirma Dockhorn (2014), certamente as tensões que se estabeleceram entre as noções de Ciência e de Método Científico com a Psicanálise mantêm-se até hoje, principal- mente sob o questionamento acerca de ser a última uma ciência ou não.

Cabe, nesta linha de raciocínio, ressaltar o que afirma Lo Bianco (2003) a respeito da virada radical na forma de investigar criada por Freud. Sabe-se que, desde o início do percurso psicanalítico, Freud buscou incluir a Psicanálise no campo das ciências. Logo, é inegável que a problemática sobre o efetivo pertencimento da Psicanálise a esse campo data de seu surgimento (Lo Bianco, 2003). Tentando lançar luz a essa discussão, a autora demonstra o quanto Freud apropriou-se do Método Científico ao longo de sua formação acadêmica e de seus trabalhos no Laboratório de Fisiologia e depois no Hospital Geral. Pode-se afirmar, portanto, não ter sido por falta de habilidade com a pesquisa empírica que Freud optou seguir outro caminho como investigador. De fato, foi por aproximar-se da concepção de Inconsciente e de suas singulares formas de expressão que novos métodos de pesquisa passaram a ser necessários. Isso ocorre, sobretudo, porque o Inconsciente não é um objeto de estudo delimitado, como são os objetos de investigação das ciências médicas (Lo Bianco, 2003). Ele se faz presente no discurso do sujeito e em sua produção psíquica tanto na esfera da psicopatologia quanto na dita normalidade.

Birman (2003) afirma que a invenção da Psicanálise ocorreu como saber mediante a formulação do conceito de Inconsciente, tornando-se potencialidade teórica e subvertendo os saberes sobre o psiquismo da época: Psiquiatria e Psicologia. Por meio da persistência na defesa da especificidade da Psicanálise, Freud criou uma nova maneira de fazer ciência, cujo rigor estava na coerência de seu método, teoria e técnica para com a premissa, antes de tudo ética, do Inconsciente. Nessa direção, enfatiza-se a condição investigativa propiciada pelo exercício de escuta na clínica psicanalítica. Para Conte (2004), submeter o trabalho clínico às indagações teóricas faz possível a renovação da Psicanálise, reavaliada por meio da pesquisa e de escritos psicanalíticos desenvolvidos no tempo e na especificidade da cultura atual.

A estratégia de pesquisa com o método psicanalítico apresentada neste artigo tem, na construção dos fatos clínicos, um fecundo elemento possível para a realização das pesquisas no cenário acadêmico. Trata-se de buscar, via fatos clínicos, uma ferramenta de pesquisa que venha a contribuir com a potencial criatividade da Psicanálise ao explorar um fenômeno, salvaguardando a especificidade de um método que 
tem na singularidade do sujeito de Inconsciente e da Sexualidade seus principais pontos de ancoragem.

\section{A pesquisa com o método psicanalítico}

Para realizar uma pesquisa psicanalítica, diferenciam-se duas possibilidades de acordo com Figueiredo e Minerbo (2006), a saber: a pesquisa em Psicanálise e a pesquisa com o método psicanalítico. A primeira refere-se ao conjunto de atividades voltadas para a produção de conhecimento que podemanter com a Psicanálise relações muito diferentes, ora tomando suas teorias como objeto de estudos sistemáticos, ora como reflexões epistemológicas. Tal prática pode ser realizada por diferentes pesquisadores, como filósofos, historiadores, etc., podendo ser a própria Psicanálise objeto da pesquisa. Já a modalidade de pesquisa com o método psicanalítico exige um psicanalista em atividade clínica, entendendo que seu olhar permite que o objeto ressurja de forma diferente, desconstruído e transformado (Figueiredo, \& Minerbo, 2006).

Nesta mesma direção - a modalidade de pesquisa com o método-, o pesquisador psicanalítico, segundo Caon (1994), caracteriza-se pela singularidade do campo, do objeto e do método de sua pesquisa. Para o autor, o campo é o Inconsciente e o objeto é o enfoque escolhido pelo pesquisador para chegar ao Inconsciente. Já o método é o procedimento pelo qual o pesquisador se movimenta pelas vias de acesso ao Inconsciente (Caon, 1994).

$\mathrm{Na}$ pesquisa com o método psicanalítico, o pesquisador tem participação ativa no processo justamente para a emergência do material. Iribarry (2003) considera que o analista, ao desenvolver uma pesquisa em Psicanálise, coloca-se como primeiro sujeito da investigação, buscando, por meio das construções sobre a prática clínica, elaborar hipóteses metapsicológicas. Ao tratar justamente sobre o tema da concepção da metapsicologia freudiana, Garcia-Roza (1984/2011) aponta que uma teoria científica não emerge de uma mera observação dos fatos. De acordo com o autor, aquele que procura conhecer determinado fenômeno está implicado subjetivamente, realizando uma observação a partir de um lugar teórico, o que possibilita produzir construções teóricas criadas com a finalidade de uma nova inteligibilidade.

Ao abordar também o tema da investigação em Psicanálise, Conte (2004) afirma que no processo de escritura de uma teoria, como em qualquer processo criativo, o sujeito se enreda com o objeto que deve descobrir ou criar para logo poder se desprender dele. Confunde-se em um movimento reflexivo para, logo, interpretar e estabelecer a diferença que dará origem a seu texto (p. 9). Segundo Dallazen, Giacobone, Macedo e Kupermann (2012), a Psicanálise pressupõe liberdade e comporta uma profunda reflexão sobre 'o desejo do analista' como uma condição necessária para o processo de análise. Lacan (1967/2003), ao cunhar a expressão 'desejo do analista', criou mais que um conceito, desenvolveu um articulador ético. Para o autor, ao manter o enigma de seu desejo, o analista permite que a função do desejo, como proveniente do lugar do Outro, possa se manifestar. Castro (2013) salienta, ainda, fundamentando-se na concepção lacaniana sobre a ética do desejo, que, na clínica psicanalítica, o analista deixa o analisante permanentemente a desejar por e para ele, sendo o desejo do analista, o desejo de nada. Dallazen et al. (2012) referem que o desejo do psicanalista não pode se sobrepor ao do analisando na condição de exercício da escuta clínica, tampouco quando estiver ocupando a posição de pesquisador. $\mathrm{Na}$ atenção à preservação da condição ética, consideram os autores que uma pesquisa com material clínico só pode ser realizada a posteriori, não transformando, portanto, o paciente em objeto de desejo durante seu tratamento. Logo, mediante a observância destes aspectos, as regras de abstinência e neutralidade que conduzem a escuta analítica ficam preservadas, garantindo ao analisando um espaço de respeito e assegurando a especificidade de deixá-lo desejar a partir de si mesmo.

A especificidade do método psicanalítico na pesquisa, segundo Figueiredo e Minerbo (2006), é a de ter a presença de um psicanalista, ou seja, um psicanalista na condução da pesquisa é uma condição sine qua non. Os autores definem a pesquisa com o método psicanalítico como uma atividade na qual objeto pesquisado, sujeito (o pesquisador) e seus meios de investigação (conceitos, técnicas) são transformados após a realização da pesquisa, produzindo, também como consequência, novidades à própria Psicanálise. Esse método pode ser utilizado para interpretar qualquer fenômeno que faça parte da realidade humana, como fenômenos sociais ou institucionais, material clínico colhido de grupos de pacientes, entrevistas, sessões de psicoterapia, bem como qualquer tipo de material apresentativo-expressivo/projetivo (Figueiredo, \& Minerbo, 2006). Enfatiza-se que este tipo de pesquisa pode ser realizado 
tanto na universidade como em instituições psicanalíticas, ambos os contextos espaços ricos de produção de conhecimento em Psicanálise.

Comumente, quando da escolha de investigar um fenômeno a partir de material clínico próprio, um psicanalista pesquisador tende a realizar um estudo de caso ou estudo de casos clínicos (Fédida, 1991; Barth, 2006; Silva, 2013). Ainda que essas modalidades de pesquisa sejam de inegável valor e importância para a construção de conhecimento em Psicanálise, cabe afirmar que a realização de um estudo de caso não é a única via de investigação psicanalítica. Assim, este artigo, afirmando o valor da associação entre pesquisa, Psicanálise e criatividade, apresenta uma modalidade de pesquisa com o método psicanalítico na qual o pesquisador faz uso do processo de construção de fatos clínicos como recurso produtor de rico material de pesquisa. Desta forma, no próprio processo de construção dos fatos clínicos, pode-se observar o exercício do proceder psicanalítico a serviço da pesquisa com o método psicanalítico.

\section{A construção dos fatos clínicos e a vitalidade do método psicanalítico na pesquisa}

Partindo-se, portanto, da possibilidade de investigar os fenômenos humanos no âmbito de pesquisa, os fatos clínicos são constituídos a partir da experiência analítica. Ou seja, para a realização de uma pesquisa com o método psicanalítico com material clínico, o psicanalista pesquisador irá dispor de fatos clínicos oriundos do exercício da escuta. O termo fato clínico, segundo Quinodoz (1994), tem origem médica e caracteriza um fenômeno observado pelo médico no paciente, sugerindo uma relação direta entre o real e o observável, devendo ser situados em suas áreas específicas. Denominam-se, então, de fatos clínicos psicanalíticos os fenômenos pertencentes à área da Psicanálise, enquadrados no contexto da relação transferencial e contratransferencial (Quinodoz, 1994). Por fato clínico psicanalítico, entende-se uma construção realizada por analista e analisando no âmbito do campo psicanalítico, partindo da relação decorrente da comunicação dos fatos ocorridos dentro e fora da sessão, dos sonhos, dos estados afetivos e do agir do analisando. Também fazem parte dessa construção a experiência do analista, bem como a teoria e a técnica utilizada e que lhe permitem atribuir novos significados aos fatos relatados (Vollmer Filho, 1994).
Os fatos clínicos psicanalíticos produzidos pelo psicanalista, segundo Quinodoz (1994), agregam tanto o sentido manifesto como o sentido latente da comunicação do paciente. O sentido manifesto representa aquilo que pode ser diretamente observado, mas somente sendo significativo na medida em que revela o conteúdo latente, de caráter inconsciente, o que interessa verdadeiramente ao psicanalista. Assim, por meio dos fatos clínicos, são permitidas a apreensão de elementos observáveis e a atribuição de um lugar a esses elementos, tornando-os objetivos e passíveis de serem comunicados (Quinodoz, 1994).

No âmbito da pesquisa, indicam Oliveira e Rosa (2002), que osfatos clínicos predispõem a uma percepção fragmentada do caso clínico em si, devido à parcialidade decorrente da inevitável seleção dos fatos retirados dos relatos clínicos produzidos pelo psicanalista. No intuito de embasar as ideias que se deseja apresentar, a inclusão ou a exclusão de determinados elementos nos fatos clínicos parte da inferência e da subjetividade do psicanalista pesquisador, cuja implicação é indispensável nesta investigação. Além disso, relatar um fato clínico é diferente de contar a história integral do analisando, na medida em que a palavra cumpre uma função redutiva, delimitando artificialmente a comunicação dos fatos clínicos. Logo, a inferência do analista em relação ao material clínico é assumida como elemento constituinte do processo de construção dos fatos clínicos.

Existem produções no setting analítico que são inacessíveis a uma pessoa estranha a ele e impossíveis de serem reproduzidas, cabendo ao pesquisador-psicanalista apresentar uma parcela do materialclínicoconstituídopelofatoclínico,podendo-se, a partir daí, extrair algum conhecimento. Ainda assim, por ser um processo longitudinal, o processo analítico permite um acompanhamento dos fatos clínicos com relativa profundidade, repetindo-se, naquele contexto, manifestações clínicas com suficiência para serem reconhecidas em sua amplitude (Oliveira, \& Rosa, 2002).

Como asseveram Jardim e Rojas Hernández (2010), os fatos clínicos são referidos como um produto textual do analista/investigador a partir de sua escuta do vivenciado em sessão com seu paciente, sendo que "a formalização da investigação surge $a$ posteriori do tratamento psicanalítico como uma construção do analista/investigador" (p. 536). Dessa forma, o que é investigado é o material produzido pelo pesquisador, fruto de seu exercício como psicanalista, a partir de seus próprios escritos e anotações 
do que foi produzido na análise. Nesta direção, Jardim e Rojas Hernández (2010) consideram que o material clínico não serve como dado empírico a ser utilizado para comprovar uma teoria, mas, sim, como uma produção que a transferência fez possível surgir como linguagem, da qual o pesquisador procurará dar conta como uma construção teórica.

Nesse sentido, cabe ressaltar que os fatos clínicos serão gerados a partir do trabalho do pesquisador em seu ofício como psicanalista, consistindo numa reflexão documental pós-fato do que foi produzido pela dupla analítica. Ressalta-se que a construção dos fatos clínicos não deve ocorrer durante $\mathrm{o}$ atendimento, pois tal processo poderia acarretar interferências na condição de escuta do analisando. Tal concepção parte da recomendação de Freud (1912/1996) acerca da não coincidência do tratamento com o estudo de caso, principalmente ao assinalar que casos clínicos, quando direcionados desde o início a objetivos científicos, estimulam a resistência do analista-pesquisador. Logo, na estratégia de pesquisa aqui defendida, ou seja, o processo de construção dos fatos clínicos ocorre a posteriori do processo analítico.

Dallazen et al. (2012) explicitam que são as memórias e as anotações do analista, estando o processo de análise encerrado, uma elaboração secundária sobre o processo analítico e o material produzido na transferência. Os autores salientam que, em uma pesquisa com material clínico, à versão criada pelo analisando somam-se as produções do analista sobre o material que escutou e as interpretações atravessadas por seu próprio Inconsciente. Dessa forma, o material a ser pesquisado não se refere ao vivido pelo analisando, mas à criação de uma ficção por aquele que o escuta, o analista/pesquisador e suas possibilidades de produção inconsciente sobre a fala de seu analisando. Trata-se de um produto oriundo do encontro entre Inconscientes que delimita um campo de trabalho e uma forma de produção/intervenção (Dallazen et al., 2012).

É esse contexto de construção a dois que abordam Dallazen et al. (2012), que pode ser relacionado ao que afirma Amorim (2004) sobre a escritura dialógica, ou seja, a possibilidade de fazer falar o outro no interior de um discurso, revelando as marcas que um outro faz num sujeito. Para a autora, "o dialogismo remete à pluralidade de vozes que constituem toda pesquisa, seja em campo, seja no texto" (p. 94), revelando que "a instabilidade do objeto polifônico é função do sistema de alteridades que se instaura no texto" (p. 128). Entre as diferentes categorias que a autora elenca de dialogismo, salienta-se a que descreve o uso que um falante/autor utiliza das palavras de um outro para suas próprias finalidades, mas ambas as palavras sendo equipotentes, pois, no momento em que se encontram, entram em relação de significado. Em virtude da alteridade de que as duas orientações interpretativas estão sempre presentes e se ouvem duas vozes na mesma palavra, sendo o sentido da palavra bivocal o construído a partir do efeito dessa dupla presença (Amorim, 2004).

Frente ao exposto, pode-se compreender que os fatos clínicos se constituem como uma palavra bivocal apresentada de forma a remeter à dialogia entre analista e analisando, narrando assim essa dupla presença. Assim, os fatos clínicos são produzidos em forma de narrativa, enfocando a apresentação do fenômeno a ser investigado. É um trabalho laborioso, pautado em anotações do psicanalista pós-sessão, em sua memória e em suas interpretações. Esse trabalho possibilita a construção da escrita de um texto com forma e conteúdo próprios, o qual representa e apresenta a dialogia do campo analítico.

O processo de construção dos fatos clínicos já indica os fundamentos teóricos nos quais se sustenta sua elaboração, diferenciando-o de uma descrição clínica. Tal afirmativa se dá, pois, diferentemente de uma descrição que visa a uma discussão clínica, esta investigação procura explorar um fenômeno, partindo dos efeitos da escuta da dinâmica singular de um processo analítico. Essa condição de reconhecimento da função ativa de construção dos fatos clínicos por parte daquele que exerce a escuta dá condições de problematizar o processo e de fomentar novas vias interpretativas, permitindo, assim, a construção posterior de novas intervenções frente à escuta de uma demanda analítica. Ainda nesta direção, evidencia-se o cuidado ético e teórico exigidos para produzir os fatos clínicos, enfocados no fenômeno a ser investigado, e não na história e descrição do caso clínico de um analisando. Assim, a narrativa produzida pelo pesquisador é consequência do singular dispêndio de um trabalho e de uma leitura aprofundada do material, retomado e reescrito, até encontrar o formato final de fatos clínicos.

Dessa forma, a construção dos fatos clínicos é própria ao ato de escrever um texto polifônico, que faz falar de um processo mais que de um sujeito, tendo em vista ter como "matéria-prima" o viven- 
ciado em um espaço subjetivo e singular como é o processo analítico. A palavra do analisando é traduzida/transformada pela e na palavra do analista, já que os fatos clínicos não visam à reprodução em exatidão do dito pelo paciente. Mais que um fenômeno, a realização de uma pesquisa com o método psicanalítico, tendo como material os fatos clínicos, investiga e problematiza o trabalho de pensar a clínica realizada pelo próprio psicanalista.

No que tange à escolha do fenômeno clínico a ser pesquisado, esta se dá a partir do desejo do pesquisador de investigar acerca de algum enigma e inquietude gerados em sua própria escuta, já que é na experiência clínica que um psicanalista tem o principal fomento de interrogações. Assim, é o vivido na prática clínica que cria o problema de pesquisa. É a busca para responder a tais inquietações que fundamenta o espírito investigativo de um psicanalista, visando ao alcance cada vez maior da Psicanálise, renovando-a em seus fundamentos.

A evolução do método psicanalítico deve-se ao espírito investigativo de seu fundador, Sigmund Freud, que, por meio do exercício clínico com seus pacientes, reformulou sistematicamente o arcabouço teórico e técnico da Psicanálise. Birman (1992) destaca que Freud usou fartamente sua experiência psicanalítica para evocar e construir exemplos paradigmáticos, criando uma sólida fundamentação para seus conceitos e escritos técnicos. É a constante atividade investigativa, ancorada no acolhimento ao desconhecido, um dos principais legados de Freud, cuja apropriação e exercício por parte de seus sucessores permitem novas construções teórico-técnicas. Trata-se, portanto, de reafirmar o caráter de abertura e de incompletude da Psicanálise como condições essenciais à sua vigência e pertinência como teoria, método e técnica.

Minerbo (2000), ao relatar suas proposições sobre estratégias de investigação em Psicanálise, refere que a clínica ou um caso clínico geram uma questão-problema a ser investigada, devendo essa ser trabalhada de forma simultânea como eixo condutor e como eixo produtor de um trabalho. A autora afirma que: "Não se trata do estudo exaustivo de um caso clínico. Tampouco o caso será utilizado como ilustração de uma questão, de uma teoria ou de uma proposição. O caso é, naturalmente, nosso ponto de partida: sem ele não haveria a questão-problema" (Minerbo, 2000, p. 27). Percebe-se aí, na leitura que tal autora faz da obra de Freud, a preocupação em desen- volver a técnica e a clínica psicanalíticas "fundamentadas por uma constante reformulação teórica feita por aqueles que a exercem. Sua preocupação central sempre foi a de fundamentar sua teoria sobre fatos clínicos e de dar respostas conceituais aos interrogantes que estes lhe colocavam" (Hornstein, 1989, p. 42). Dessa forma, compreende-se que, através da análise dos fatos clínicos construídos pelo psicanalista, pode-se produzir conhecimento psicanalítico.

\section{Procedimentos para análise dos fatos clínicos}

Os princípios éticos da Psicanálise servem de suporte teórico e técnico para a compreensão da singularidade do fenômeno retratado em uma pesquisa com o método psicanalítico. A Psicanálise propõe um sujeito de Inconsciente, reconhecido naquilo que lhe é particular, sendo, de acordo com Dockhorn e Macedo (2008), um eficiente instrumento de reflexão e indagação a respeito da experiência humana.

Os fatos clínicos, como material de pesquisa, são analisados segundo o método psicanalítico, o que resulta, de acordo com Figueiredo e Minerbo (2006), "em efetuar certos recortes que não são arbitrários, pois vão sendo solicitados pela própria análise em andamento e se transformam à medida que a análise transcorre" (p. 274). Os dados que ilustram o processo de construção dos fatos clínicos no presente artigo se constituíram a partir da narrativa que decorreu do trabalho com o material clínico de posse do pesquisador. Como argumenta Birman (1992), o fato não existe em si, ele é a representação que o sujeito lhe designa. A narrativa, segundo o autor, é endereçada ao analista/pesquisador, que se oferece como um intérprete ao objeto através de sua escuta, baseando-se no caráter empírico da experiência da transferência.

Corroborando essa ideia, Iribarry (2003) afirma que a escuta e a transferência instrumentalizam o pesquisador em relação ao texto que sustenta a análise dos dados na pesquisa psicanalítica. O pesquisador busca identificar significantes nos dados trazidos pela investigação. Ao proceder assim, é buscado um sentido que traga uma contribuição original para o problema de pesquisa, diferenciando-se, em termos de método, o método psicanalítico do método de análise de conteúdo e de análise do discurso. A análise de conteúdo, desenvolvida por Laurence Bardin (1977), tem por objetivo a categorização de respostas para poste- 
rior interpretação dos dados, podendo ser um método decomposto em diferentes etapas de trabalho com os dados obtidos. É possível ao pesquisador relacionar e interpretar os dados com a corrente teórica que sustenta seu estudo, criando novas possibilidades de produção de conhecimento através da inferência. Já a análise do discurso, de acordo com Silva (2005), procura detectar em um texto como ele se apresenta detentor de uma materialidade simbólica própria e significativa. Este artigo, ao abordar a potencialidade investigativa de fatos clínicos, marca a especificidade do método psicanalítico de pesquisa, exatamente ao incluir como elementos essenciais o trabalho com a escuta, com a abstinência e com os aspectos transferenciais, o que não ocorre com os outros dois métodos mencionados.

Ao trabalhar o material de pesquisa com o método psicanalítico, o pesquisador realiza uma leitura dirigida pela escuta, correlata à escuta na prática clínica de seus pacientes, sustentada na técnica da atenção livre e flutuante (Caon, 1994; Iribarry, 2003). O recurso principal para abordar os fatos clínicos é a interpretação. É o trâmite da interpretação, como afirmam Figueiredo e Minerbo (2006), "que funciona como eixo para a escuta/recorte de novos fragmentos, os quais, quando interpretados, terão a mesma função com relação ao material que virá" (p. 274). Segundo os autores, os achados, a partir do material analisado, determinarão os rumos da interpretação, podendo ser a contratransferência de um analista, a título de exemplo, o elemento utilizado para instalar o horizonte da interpretação.

Conte (2004) aporta importante elemento a esta discussão ao abordar a alteridade que o pesquisador cria ao colocar-se frente ao texto. É essa posição dealteridade, evocada pelo pesquisador que, segundo a autora, cria o elemento que o habilita a criar novas interpretações do texto na abertura de brechas geradas na desconstrução do que está dado. Como indica Conte (2004):

Por meio dessa desconstrução, algo transformador e produtivo pode se revelar e, assim, produzir novos sentidos, conhecimento e teorias. Essa ideia de 'desmontar' remete à busca de elementos que nos colocam diante da nova lógica do texto e, a partir daí, ampliam-se as formas de compreensão do que estamos desvendando. Ampliamos, desse modo, as maneiras de reorganização (p. 9).

Nessa direção corrobora-se, também, a afirmativa de Green (2008) sobre não importar a credibilidade de uma interpretação, uma vez que a aceitação ou o rechaço não tem nenhuma utilidade no julgamento do valor de uma interpretação. De fato, ressalta o autor serem as vicissitudes provocadas pela interpretação o que evidencia sua fertilidade ou sua esterilidade. No caso da pesquisa em Psicanálise, como afirma Dockhorn (2014), pode-se pensar que as interpretações produzidas jamais terão o objetivo de responder permanentemente e/ou circunscrever o fenômeno estudado; na verdade, terão por objetivo ampliar o olhar e promover uma abertura para novas compreensões do fenômeno. Trata-se, portanto, de interpretar o que se oferece à possibilidade de conhecimento e não de esgotá-lo ou de enunciar dogmas a partir da construção de enunciado.

A forma de trabalhar o material para a construção de fatos clínicos reafirma o proposto por Magtaz e Berlinck (2012) sobre o fato de que a interpretação de um caso não contém uma dimensão explicativa, isto é, o caso não deve ser explicado em seu relato, como se faz no método do estudo de caso. Os autores propõem que "o caso clínico é porta-voz de um problema de investigação e fundamento da pesquisa" (p. 71), sendo investido pelo pesquisador a partir do que o instigou ou surpreendeu, fazendo-o formular uma questão enigmática e traçar um caminho a ser seguido para respondê-la. Magtaz e Berlinck (2012) argumentam que o caso é do clínico e não do paciente, pois se trata, na formulação e interpretação do material, do clínico e de seu desejo de transformar sua vivência em experiência compartilhada, por meio de um tema de investigação.

Para Conte (2004), a interpretação, como método clínico, deve ampliar o sentido, fazendo circular representações ou significantes que ofereçam novas possibilidades de simbolização. Muitos são os elementos a se levar em conta em uma interpretação, segundo a autora, como, por exemplo, a subjetividade, o Inconsciente, a realidade dada e o estranho. O próprio conceito psicanalítico de Inconsciente demonstra que não é possível reduzi-lo a um conhecimento absoluto, já que "nem tudo é dito, nem tudo é conhecimento e nem tudo pode se reorganizar no psiquismo; porém, a intervenção faz brotar algo, recoloca, no processo, novos elementos" (Conte, 2004, p. 9). Já a interpretação de um texto ou documento, à luz da Psicanálise, remete à desconstrução como uma estratégia para fazer um recorte teórico-metodológico considerando-se o que pesquisa o psicanalista. É por meio da desconstrução, confrontando a teoria do texto com um novo, que o pesquisador psicanalista realiza a transformação em 
algo produtivo, capaz de produzir novos sentidos, conhecimentos e teorias (Conte, 2004).

A Psicanálise, como singular procedimento de investigação, de acordo com Jardim e Rojas Hernández (2010), toma por objeto de estudo os processos psíquicos inconscientes originários da sessão analítica, revelando que no tratamento o percurso e a investigação psicanalítica são complementares, sendo a clínica a base e a origem dessa investigação. Portanto, para as autoras, a investigação mostra a posteriori o que surge a partir da escuta de pacientes em análise, não sendo possíveis nem necessárias a demonstração e a comprovação, pois os fatos clínicos obtidos são uma construção do analista/investigador a partir da escuta do Inconsciente. Nesse sentido, as autoras afirmam que o "saber do inconsciente não é buscado como se busca conhecer aos objetos de estudo na explicação das ciências cartesianas, o inconsciente é encontrado, e a forma de fazê-lo não se estabelece seguindo métodos positivistas, por ser um saber que não é possível controlar ou quantificar" (Jardim, \& Rojas Hernández, 2010, p. 535).

O método para conhecer os produtos do Inconsciente se dá através do recurso à palavra e ao ato. Como acrescentam Rosa e Domingues (2010), "mais do que pelo tema e lugar, a pesquisa em psicanálise se define pela maneira de formular as questões. [...] $\mathrm{O}$ objeto da pesquisa não é dado a priori, mas sim produzido na e pela investigação" (p. 182). Conforme as autoras, o método de pesquisa em Psicanálise possui uma dimensão própria de sujeito e de objeto, contrapondo-se ao método da ciência calcado no cogito cartesiano. A ideia proposta por Lacan, lá onde penso não sou, é resultado da torção do cogito cartesiano penso, logo existo. Lacan (1957/1998; 1966/1998), ao introduzir o que é da ordem do inconsciente no cogito, aponta uma separação entre ser e pensar, passando a consciência e a razão a representar o lugar do engano. Contribuindo para essa discussão, Jardim e Rojas Hernández (2010) consideram que a relevância da Psicanálise é acentuada no seu interesse em abordar o que a ciência cartesiana deixa de fora, ou seja, "o sujeito da ciência é o sujeito que a Psicanálise se interessa em investigar, porque à Psicanálise se coloca como objeto de investigação o inconsciente do sujeito" (p. 531).

É, portanto, na dimensão da singularidade que se situa a Psicanálise e a pesquisa com o método psicanalítico. A partir dos argumentos de que a Psicanálise tem seus instrumentos e seu corpus próprio de investigação, ela pode se afirmar como um legítimo método de pesquisa, com fundamentação e embasamentos técnicos e éticos próprios. Assim, é importante fomentar o conhecimento da produção decorrente desta modalidade de investigação, cujo rigor está calcado na própria especificidade desta disciplina. Na análise dos fatos clínicos no modelo aqui proposto, o psicanalista-pesquisador realiza a leitura dos fatos clínicos repetidas vezes, quantas vezes forem necessárias, objetivando elencar eixos interpretativos que suscitam do material, criando uma nova forma de abordar o fenômeno estudado. Tal processo requer tempo, sendo utilizada aí, nas leituras e releituras feitas, a atenção flutuante, tal como a aplicação do método psicanalítico na prática clínica.

Tendo como pano de fundo o fenômeno a ser estudado, o pesquisador passa a ler o material de forma a não privilegiar elementos do texto, deixando agir aí o seu Inconsciente. É por meio desta singular forma de ler e reler o material, ou seja, o seu corpus de dados, que teorizações podem passar a alicerçar os eixos interpretativos que surgirão da análise do material. Uma pesquisa com o método psicanalítico aproxima-se, assim, a um estudo com características da pesquisa documental em que são trabalhados os materiais produzidos pelo pesquisador a partir de documentos, contudo, com o objetivo, agora, não de construção de fatos históricos, e sim de fatos clínicos.

Dallazen et al. (2012) apontam que, para uma comunidade científica produzir um conhecimento consistente e marcado pela responsabilidade, é necessária a observância dos fatores éticos em todas as etapas, não deixando de lado a existência das especificidades próprias dos diferentes campos do saber. Para a interface da Psicanálise com a pesquisa devem ser respeitadas suas especificidades, permitindo a produção de conhecimento, que tem na clínica o seu principal fomento. Os autores abordam a inviabilidade de um processo analítico frente a imposição de um desejo específico do analista. Quando o psicanalista inclui numa sessão um pedido que é regido por seu interesse de pesquisar um tema ou um sujeito, a ética própria à Psicanálise é rompida, já que não estaria mais sendo abstinente e neutro para exercer a escuta. $\mathrm{O}$ analisando teria que lidar com uma demanda que não é sua, não sendo o que lhe traz à análise, comprometendo, assim, a transferência e o vínculo de confiança necessários para o andamento do processo (Dallazen et al., 2012). 
Dessa forma, a fim de realizar uma pesquisa com fatos clínicos, sugere-se que as questões éticas envolvidas neste tipo de estudo devam ser observadas a partir dos seguintes tópicos, conforme encontrado em Dallazen (2010):

- Sigilo: não devem ser mencionados nem utilizados quaisquer dados ou informações que possam revelar a identidade ou identifiquem o sujeito (analisando).

- Pós-fato: o processo de análise que gera os fatos clínicos deve ter sido encerrado antes do início do estudo.

- Recurso à técnica reconhecida: cabe ressaltar que os fatos clínicos resultam de um processo de tratamento cuja técnica utilizada é reconhecida pela ciência e pelo Conselho Federal de Psicologia, ou seja, se refere a um processo terapêutico conduzido mediante o emprego de uma técnica consagrada que é a Psicanálise, ficando garantidos a integridade física e $o$ emocional do sujeito.

\section{Os fatos clínicos em uma ilustração de aplicação do método psicanalítico à pesquisa}

A fim de explorar o fenômeno da transferência como um entrave no processo de escuta psicanalítica, foi realizada uma pesquisa com o método psicanalítico tomando como base uma experiência clínica cujo processo foi interrompido pelo analisando. O objetivo foi investigar a dinâmica do processo transferencial na condução da análise com vistas a articular os fenômenos da transferência e os entraves à escuta psicanalítica. Buscou-se problematizar aqui os alcances e limitações da técnica psicanalítica. Assim, passou-se a explorar a singularidade de uma manifestação transferencial como sendo a principal matéria-prima do estudo. Enfatizou-se a importância de explorar os sentidos do processo analítico quando a transferência se apresenta como uma resistência à escuta analítica. Tratou-se, portanto, de uma investigação que envolveu a intersecção dos três elementos constituintes da Psicanálise: a teoria, o método e a técnica, além da ética que aí se subentende e que amarra esses três elementos. Na conjunção destes três elementos se renova o caráter de abertura da Psicanálise e se dá a possibilidade de buscar novos conhecimentos que venham a promover, cada vez mais, a sua condição de essencial ferramenta de leitura e compreensão dos fenômenos humanos, desde que respeitada a premissa ética que subjaz ao 'desejo do analista'.

Os fatos clínicos que compuseram o estudo eram provenientes do trabalho da pesquisadora com o material decorrente da análise de um analisando atendido já faz alguns anos, durante um curto período de tempo. A partir de um olhar retrospectivo sobre $\mathrm{o}$ atendimento ocorrido e interrompido, foram feitos recortes sobre o vivenciado pela analista nas sessões com o analisando. Tendo como base anotações e registros na memória decorrentes da situação clínica de escuta, ocorreu a escrita do texto e a construção dos fatos clínicos. O material foi reescrito tantas vezes quanto fosse necessário para que apresentasse o fenômeno a ser investigado, respeitando os aspectos éticos a serem considerados na apresentação do material.

A produção dos fatos clínicos possibilitou a construção de uma narrativa, a qual expunha as modalidades de transferência estabelecidas durante esse processo, bem como enfatizava os entraves percebidos e analisados à época. Para tanto, o trabalho que ilustra este artigo se deu em três etapas. Trata-se, cabe ressaltar, de uma sistemática de trabalho elaborada para este estudo, o que não configura uma exigência ao processo de construção dos fatos clínicos. Coerente aos pressupostos teóricos da Psicanálise e à ética que lhes são inerentes, não se trata aqui de indicar "procedimentos" a serem reproduzidos em outros estudos, mas, sim, indicar que essas três etapas foram orientadoras do trabalho de pesquisa aqui exemplificado e surgiram da própria leitura do material e da apreensão singular realizada pelo psicanalista-pesquisador na construção de sua investigação. Como bem afirma Dockhorn (2014), em um processo de pesquisa com o método psicanalítico não se trata de apresentar ou propor critérios predeterminados, uma vez que tal situação esgotaria a necessária criatividade exigida do psicanalista-pesquisador diante dos dados produzidos na singularidade de seu estudo.

Na primeira etapa, optou-se por descrever a chegada do sujeito à análise e como foi se apresentando à escuta da analista. A segunda etapa do processo de construção dos fatos clínicos apresentou e explorou as hipóteses interpretativas da analista que ocorreram durante o processo analítico a partir da escuta do analisando. A última etapa referiu-se à pesquisa com o método psicanalítico propriamente 
dito. Nela, mediante análise dos fatos clínicos apresentados na investigação, novas interpretações da transferência foram estabelecidas. Assim, ocorreu importante ampliação de sentidos próprios à dinâmica transferencial, bem como pôde-se explorar a singularidade dos entraves gerados na contratransferência ocorrida naquele processo de escuta. Esta última etapa permitiu, por meio do método psicanalítico de pesquisa e do recurso da interpretação, uma nova "escuta" do material do paciente e dos efeitos transferenciais e contratransferenciais, viabilizando a emergência de novos eixos interpretativos, nomeados e problematizados, posteriormente, com o auxílio dos conceitos fundamentais da teoria e da técnica psicanalíticas.

Cabe ressaltar que todas as etapas de construção e realização do trabalho investigativo possibilitaram à analista-pesquisadora situar-se em novas leituras a respeito do fenômeno clínico, fomentando o aprendizado consistente da complexidade da escuta analítica e seus desafios. Resgatar uma experiência analítica por meio da construção de fatos clínicos e do posterior trabalho interpretativo tornou possível problematizar os entraves transferenciais que adentraram a escuta e podem ter fomentado, inclusive, a interrupção do processo de análise. Nesta experiência de pesquisa com fatos clínicos, confirmou-se ser a interpretação, calcada na escuta atenta e flutuante, o instrumento de acesso à singularidade dos fenômenos transferenciais próprios ao processo analítico. O trabalho com os fatos clínicos permitiu à pesquisadora-psicanalista trazer à discussão elementos referentes à formação psicanalítica, o início da prática clínica, a experiência de escuta propriamente dita, bem como de outros não menos importantes aspectos. Acredita-se que trabalhar os fatos clínicos com a interpretação permitiu desdobrar seus sentidos e desvelar distintas nuances do processo de escuta do sofrimento subjetivo gerado pelo sintoma. Assim, confirmou-se ser necessária a presença de um psicanalista no exercício da pesquisa com o método psicanalítico.

Nesse constante movimento de revisitar o fazer analítico, vitalizam-se a teoria e a prática. Logo, é inegável o valor de relançar a teoria e a técnica a partir de cada experiência singular da clínica, fomentando o exercício reflexivo do analista sobre seu fazer propiciando, desse modo, discussões fundamentais e necessárias para a ampliação da Psicanálise. As inter- pretações produzidas são sempre provisórias e relativas ao contexto de onde surgiram. Ao emergirem a partir da leitura dos fatos clínicos, as interpretações têm um caráter interminável, podendo suscitar novas leituras do material. É esta característica de abertura a riqueza da Psicanálise, que dá espaço a novas significações e a novos caminhos investigativos para a abordagem da subjetividade humana.

\section{À Guisa de Conclusão}

Entre os achados da pesquisa com o método psicanalítico, ganha destaque a constatação de quão profícua é a aproximação entre a Psicanálise e a pesquisa no âmbito acadêmico. Assim, tal aproximação explicita que as reflexões e os interrogantes surgidos no trabalho clínico de um psicanalista podem gerar um tema de pesquisa e viabilizar que este seja acolhido nas investigações que acontecem no cenário da Universidade, e mesmo nas Instituições Psicanalíticas. O maior ganho decorre da possibilidade de fomentar, também por meio da pesquisa na Academia, outras formas de produzir conhecimento em Psicanálise, tendo as inquietações e/ou impasses da clínica como fonte de inspiração e de provocação. Cabe salientar, portanto, que a pesquisa efetivada na Universidade pode ser fruto de interrogações sobre as condições técnicas de psicanalisar e, ao mesmo tempo, promover, na sistematização criativa e não pré-determinada de suas etapas, um espaço de exercício reflexivo e estudo para um psicanalista no intuito de produzir conhecimento em Psicanálise no âmbito da Academia. Permite-se, desta forma, alinhar a ética e a especificidade da Psicanálise com o rigor metodológico exigido no espaço acadêmico. Assim, também um psicanalista pode exercer suas habilidades de pesquisador para além, mas sempre a partir de sua clínica.

Sem dúvida, o corpo teórico, o método e a técnica da Psicanálise têm muito a contribuir para a produção de conhecimento oriunda das Universidades. A prática de pesquisa mostra-se, portanto, como um fértil campo a ser ocupado por psicanalistas. Reconhecer o valor desse espaço não significa desconhecer os impasses presentes nas pesquisas em Psicanálise feitas no cenário acadêmico, marcados pelo confronto com critérios de validade e fidedignidade próprios à ciência positivista. O enfrentamento de críticas quanto ao método de pesquisa, quanto 
à interpretação dos achados, bem como sua não replicação e não generalização, são tensionamentos presentes nesse contexto. Para incrementar a reflexão a respeito desta realidade, retoma-se a afirmativa de Dockhorn (2014) no sentido de que, diante das reais dificuldades de trabalho acadêmico em relação ao material oriundo do exercício clínico da Psicanálise:

Parece ter o psicanalista-pesquisador duas alternativas: permanecer numa posição defensiva diante da afirmação da impossibilidade de essa modalidade de pesquisa fazer-se presente no cenário universitário, rebatendo as críticas com o velho argumento da resistência provocada pela Psicanálise, ou imbuir-se de um trabalho criativo que atenda à especificidade e ao rigor próprios à Psicanálise no intuito de demarcar sua legítima inserção - mesmo que diferenciada - no cenário da Universidade (p. 72).

Neste artigo, optou-se por ilustrar a escolha pelo enfrentamento do desafio de realizar um trabalho criativo na pesquisa com o método psicanalítico. O processo de construção de fatos clínicos solidificou-se como uma fértil possibilidade de pesquisa com o método psicanalítico na Universidade, não deixando dúvidas quanto à atenção e cuidado dispensados à especificidade da Psicanálise como campo diferenciado de saber, mas, que também, pode marcar sua presença no espaço de produção de conhecimento em ciências humanas.

No que se refere ao uso de fatos clínicos em uma pesquisa com o método psicanalítico, afirma-se a riqueza destes para articular aspectos da teoria e da técnica, embasados em um processo singular. É na dimensão da singularidade que se constroem a Psicanálise e a pesquisa com o método psicanalítico. Somado a isso, uma pesquisa com este tipo de material possibilita demonstrar o vigor interpretativo da Psicanálise diante dos variados fenômenos clínicos, sempre que se toma a especificidade do método psicanalítico como recurso metodológico. Constata-se, assim, que o recurso a este método de pesquisa permite a emergência de novos eixos de interpretação, gerando um trabalho de ressignificação do material e qualificação do trabalho analítico.

Em Psicanálise, um processo de escuta é fundamentado na capacidade de investigação dos processos psíquicos inconscientes. Na base da formação do psicanalista está sua condição de investiga-dor, enfatizando-se, assim, o papel decisivo de escuta do sujeito de Inconsciente. Como objeto de estudo da Psicanálise, a própria complexidade do sujeito de Inconsciente, convoca ao sistemático exercício investigativo em Psicanálise. Nas etapas próprias ao processo de construção e de interpretação dos fatos clínicos, como apresentado neste artigo, é possível observar e constatar que, aliam-se, na investigação, os elementos essenciais de um processo analítico: a escuta, a abstinência, a transferência e a interpretação.

A relevância e a pertinência de investigações com o método psicanalítico relacionam-se à vitalidade da escuta e da criatividade e inovação presentes e viabilizadas nas pesquisas psicanalíticas, retomando e renovando os fundamentos de seu saber e de sua prática, ao mesmo tempo em que estimula fortemente a investigação em Psicanálise como relevante forma de seguir trabalhando e ampliando o legado freudiano. Deve o psicanalista, no exercício de seu ofício, manter-se crítico quanto às condições de seu fazer, possibilitando, através da problematização de seus questionamentos e da condição de compartilhar seus achados, sistematizar suas investigações, fazendo assim avançar a Psicanálise como teoria, método e técnica sustentados na 'ética do desejo'.

Sabe-se que a história e o valor do legado psicanalítico não permitem equivaler a Psicanálise a uma prática dogmática e completa. Freud (1923/1996) já afirmava que a Psicanálise não era como a Filosofia, que parte de conceitos básicos bem definidos e procura apreender todo o universo com o auxílio deles. Ao contrário, para seu fundador, a Psicanálise é: "Sempre incompleta e sempre pronta a corrigir ou modificar suas teorias. Não há incongruência (não mais que no caso da física ou da química) se a seus conceitos mais gerais falta clareza e seus postulados são provisórios; ela deixa a definição mais precisa deles aos resultados do trabalho futuro" (Freud, 1923/1996, p. 269-270).

Portanto, entende-se que para a Psicanálise a condição de interrogante faz parte da sustentação de sua vigência. Assim, afirma-se que práticas de pesquisa com o método psicanalítico alinham-se, legitimamente, nesta intenção de manter em aberto o conhecimento teórico e clínico. A prática da pesquisa pode e deve fomentar a produção de conhecimento em Psicanálise sem afastar-se do valor anunciado no reconhecimento e assunção da necessidade de seguir trabalhando em e pela Psicanálise para que seu devir possa ser coerente com seu nascimento inovador. 


\section{Referências}

Amorim, M. (2004). O pesquisador e seu outro: Bakhtin nas ciências humanas. São Paulo, SP: Musa Editora.

Bardin, L. (1977). Análise de conteúdo. Lisboa: Edições 70.

Barth, L. (2006). Da figuração à transfiguração da fantasia na construção do caso: as ficções metapsicológicas (Tese de doutorado). Curso de Pós-Graduação em Psicologia do Desenvolvimento, Universidade Federal do Rio Grande do Sul, Porto Alegre, RS.

Birman, J. (1992). A clínica na pesquisa psicanalítica. In Atas do 20 Encontro de pesquisa acadêmica em psicanálise: psicanálise e universidade (p. 7-37). São Paulo: PUC-SP.

Birman, J. (2003). Freud \& a filosofia. Rio de Janeiro, RJ: Jorge Zahar.

Caon, J. (1994). O pesquisador psicanalítico e a situação psicanalítica de pesquisa. Psicologia: Reflexão $e$ Crítica, 7(2), 145-174.

Castro, J. (2013). Psicanálise: ética, discurso e ensino. Curitiba, PR: Appris.

Conte, B. (2004). Reflexões sobre o método e a metodologia em psicanálise. Revista da Sociedade de Psicologia do Rio Grande do Sul, 1(3), 6-10.

Dallazen, L. (2010). O superego e o ideal do ego: um destino ao romance familiar (Dissertação de Mestrado). Programa de Pós-Graduação em Psicologia Clínica, Universidade de São Paulo, São Paulo, SP.

Dallazen, L., Giacobone, R. V., Macedo, M. M. K., \& Kupermann, D. (2012). Sobre a ética em pesquisa em psicanálise. Psico, 43(1), 47-54. Recuperado de http://revistaseletronicas.pucrs.br/ojs/index.php/ revistapsico/article/view/11098/7618

Dockhorn, C. N. B. F. (2014). O sujeito psíquico e a condição de servidão ao objeto-droga: do rigor da psicanálise à pesquisa na escuta (Tese de doutorado). Pontifícia Universidade Católica do Rio Grande do Sul, Porto Alegre, RS.

Dockhorn, C. N. B. F., \& Macedo, M. M. K. (2008). A complexidade dos tempos atuais: reflexões psicanalíticas. Psicologia Argumento, 24(56), 217-224. Recuperado de http://www2.pucpr.br/reol/pb/index. $\mathrm{php} / \mathrm{pa}$ ?dd $1=2496 \& d d 99=$ view $\&$ dd98 $=\mathrm{pb}$

Dunker, C. I. L. (2011). Estrutura e constituição da clínica psicanalítica: uma arqueologia das práticas de cura, psicoterapia e tratamento. São Paulo, SP: Annablume.
Fédida, P. (1991). A construção do caso. In Fédida, P. Nome, figura e memória: a linguagem na situação psicanalítica (pp. 215-236). São Paulo, SP: Escuta.

Figueiredo, L. C., \& Minerbo, M. (2006). Pesquisa em psicanálise: algumas ideias e um exemplo. Jornal de Psicanálise, 39(70), 257-278. Recuperado de http:// pepsic.bvsalud.org/scielo.php?script=sci_abstract\&pid=S0103-58352006000100017

Freud, S. (1996). Estudos sobre a histeria. In J. Strachey (Ed., Trad.). Edição standard brasileira das Obras psicológicas completas de Sigmund Freud (v. 2, pp. 13-27). Rio de Janeiro, RJ: Imago. (Trabalho originalmente publicado em 1895).

Freud, S. (1996). Fragmento da análise de um caso de histeria. In J. Strachey (Ed. Trad.). Edição standard brasileira das Obras psicológicas completas de Sigmund Freud (v. 7, pp. 15-116). Rio de Janeiro, RJ: Imago. (Trabalho originalmente publicado em 1905).

Freud, S. (1996). Recomendações aos médicos que exercem a psicanálise. In J. Strachey (Ed., Trad.). Edição standard brasileira das Obras psicológicas completas de Sigmund Freud (v. 12, pp. 123-133). Rio de Janeiro, RJ: Imago. (Trabalho originalmente publicado em 1912).

Freud, S. (1996). Os instintos e suas vicissitudes. In J. Strachey (Ed., Trad.). Edição standard das Obras psicológicas completas de Sigmund Freud (v. 14, pp. 115-144). Rio de Janeiro, RJ: Imago. (Originalmente publicado em 1915).

Freud, S. (1996). Dois verbetes de enciclopédia. In J. Strachey (Ed., Trad.). Edição standard brasileira das Obras psicológicas completas Sigmund Freud (2a ed., v. 18, pp. 251-274). Rio de Janeiro, RJ: Imago. (Trabalho originalmente publicado em 1923).

Garcia-Roza, L. A. (2011). Freud e o inconsciente. Rio de Janeiro, RJ:Zahar. (Originalmente publicado em 1984).

Green, A. (2008). Orientações para uma psicanálise contemporânea. Rio de Janeiro, RJ: Imago.

Hornstein, L. (1989). Introdução à psicanálise. São Paulo, SP: Escuta.

Iribarry, I. N. (2003). O que é pesquisa psicanalítica? Ágora (Rio de Janeiro), 6(1), 115-138. doi:10.1590/S1516-14982003000100007

Jardim, L., \& Rojas Hernández, M. (2010). Investigación psicoanalítica en la universidad. Estudos de Psicologia (Campinas), 27(4), 529-536. doi:10.1590/S0103-166X2010000400010 
Lacan, J. (1998). A ciência e a verdade. In Lacan, J. Escritos (pp. 869-892). Rio de Janeiro, RJ: Jorge Zahar. (Originalmente publicado em 1966).

Lacan, J. (1998). A instância da letra no inconsciente ou a razão desde Freud. In Lacan, J. Escritos (pp. 496-533). Rio de Janeiro, RJ: Jorge Zahar. (Originalmente publicado em 1957).

Lacan, J. (2003). Proposição de 9 de outubro de 1967 sobre o psicanalista da Escola. In Lacan, J. Outros escritos (pp. 248-264). Rio de Janeiro, RJ: Jorge Zahar. (Originalmente publicado em 1967).

Lo Bianco, A. C. (2003). Sobre as bases dos procedimentos investigativos em psicanálise. Psico-USF, 8(2), 115-123. doi:10.1590/S1413-82712003000200003

Magtaz, A. C., \& Berlinck, M. T. (2012). O caso clínico como fundamento da pesquisa em psicopatologia fundamental. Revista Latinoamericana de Psicopatologia Fundamental, 15(1), 71-81. doi:10.1590/S1415-47142012000100006

Minerbo, M. (2000). Estratégias de investigação em psicanálise: desconstrução e reconstrução do conhecimento. São Paulo, SP: Casa do Psicólogo.

Moraes, E. G., \& Macedo, M. M. K. (2011). Vivência de indiferença: do trauma ao ato-dor. São Paulo, SP: Casa do Psicólogo.

Oliveira, M. D., \& Rosa, J. T. (2002). Fatos clínicos psicanalíticos na psicoterapia de uma paciente com depressão narcísica. Mudanças, 1(1), 11-40. Recuperado de http://pesquisa.bvs.br/brasil/resource/pt/lil-360578

Quinodoz, J. M. (1994). Fatos clínicos ou fatos clínicos psicanalíticos? Revista Brasileira de Psicanálise, 28(4), 613-34.

Rosa, M. D., \& Domingues, E. (2010). O método na pesquisa psicanalítica de fenômenos sociais e políticos: a utilização da entrevista e da observação. Psicologia \& Sociedade, 22(1), 180-188. doi:10.1590/S0102-71822010000100021

Silva, D.Q. (2013).A pesquisa empsicanálise: o método de construção do caso psicanalítico. Estudos de Psicanáli- se, 39,37-45.Recuperadodehttp://pepsic.bvsalud.org/ scielo.php?pid=S0100-34372013000100004\&script=sci_abstract

Silva, M. A. S. M. (2005). Sobre a análise do discurso. Revista de Psicologia da UNESP, 4(1), 16-40. Recuperado de http://186.217.160.122/revpsico//index. $\mathrm{php} /$ revista/article/viewFile/30/55

Vollmer Filho, G. (1994). A conceituação do fato clínico psicanalítico. Revista Brasileira de Psicanálise, 28(4), 673-85.

\section{Clarice Moreira da Silva}

Psicóloga, Psicanalista, Mestre pela Pontifícia Universidade Católica do Rio Grande do Sul, Porto Alegre-RS. Brasil.

E-mail: claricems@gmail.com

Mônica Medeiros Kother Macedo

Psicóloga, Psicanalista, Doutora e Docente da Pontifícia Universidade Católica do Rio Grande do Sul, Porto Alegre - RS. Brasil.

E-mail:monicakm@pucrs.br

Endereço para envio de correspondência:

Pontifícia Universidade Católica do Rio Grande do Sul, Av. Ipiranga 6681, prédio 11, $8^{\circ}$ andar - Partenon.

CEP: 90619-900.

Porto Alegre - RS. Brasil.

Recebido 13/07/2014

Reformulado 26/04/2015

Aprovado 29/04/2016

Received 07/13/2014

Reformulated 04/26/2015

Approved 04/29/2016

Recibido 13/07/ 2014

Reformulado 26/04/2015

Aceptado 29/04/2016

Como citar: Silva, C. M., \& Macedo, M. M. K. (2016). O método psicanalítico de pesquisa e a potencialidade dos fatos clínicos. Psicologia: Ciência e Profissão, 36(3): 520-533. doi:10.1590/1982-3703001012014

How to cite: Silva, C. M., \& Macedo, M. M. K. (2016). The psychoanalytic method of research and the potential of clinical facts. Psicologia: Ciência e Profissão, 36(3): 520-533. doi:10.1590/1982-3703001012014

Cómo citar: Silva, C. M., \& Macedo, M. M. K. (2016). El método psicoanalítico de investigación y la potencialidad de los hechos clínicos. Psicologia: Ciência e Profissão, 36(3): 520-533. doi:10.1590/1982-3703001012014 